\title{
Bird Migration in Relation to Foot-and-Mouth Disease.
}

\author{
By A. Landsborough Thomson, O.B.E., D.Sc.
}

\begin{abstract}
A PAPER with the title "Bird Migration and A the Introduction of Foot-and-Mouth Disease" appears in The Journal of the Ministry of Agriculture for November I923 (vol. xxx., No. 8, p. 68I). The authors are Sir Stewart Stockman, Chief Veterinary Officer of the Ministry, and Miss Marjory Garnett, the former being responsible mainly for the veterinary information and the latter for the ornithology. Their purpose is to discuss whether migratory birds may possibly be the means of introducing fresh infections of foot-and-mouth disease into Great Britain. The available evidence is admittedly circumstantial, and the authors start with the assumption that it is impossible to prove a positive case, but that it is practicable to inquire whether the question can be disposed of by establishing a negative. Having thus disavowed any intention of engaging in special pleading, they proceed to state the arguments in favour of the theory that birds may be the responsible agents.

Throughout the paper the question is confined to "initial outbreaks of invasion," as distinct from " outbreaks of ramification from the former," and of these there are said to have been eighty in twentytwo years. Mystery enshrouds the origin of these original outbreaks, which may occur months or years after the country has been free from infection, and commonly arise at places which had not previously harboured cases of the disease. The entry of ruminants and swine was totally forbidden during the period, as also the importation of straw and hay from infected countries. All outbreaks were dealt with by slaughter, so that the possibility of recovered "carriers" is excluded, and all infected premises were disinfected and then kept isolated for a time. Inquiries made in every case usually failed to reveal any obviously possible source of infection.
\end{abstract}

For these reasons it is assumed that the initial outbreaks are due to the importation of the virus from abroad by some unknown means, and it is noted that they occur during waves of prevalence of the disease on the Continent. It is then argued that birds constitute a possible means of introduction. Three ways are suggested : the birds might themselves contract some form of the disease, although this is not actually known to occur, and birds have usually proved highly insusceptible in experiments; the birds might infect pastures with virus carried on their feet or plumage, which is not inherently impossible in view of the known carriage of the virus in straw, hay, clothing, and the like; or the birds might swallow the virus and excrete it uninjured, although the viability of the virus under these conditions is not discussed.

The main theme of the paper is the connexion, if any, between the seasonal and geographical incidence of initial outbreaks of disease and the known immigratory movements of birds from the Continent. This is simplified by the fact that foot-and-mouth disease is rare in countries north of Denmark, and that the autumn and winter immigrations of birds from the north-west, north, and north-east may therefore be disregarded. The question thus resolves itself into that of a possible correlation between the introduction of disease and (a) autumn and winter immigration and passage from the east on the southern portion of the east coast of England, and $(b)$ spring and summer immigration and passage from the south.

The authors argue that there is indeed good evidence of a correspondence between the epidemiological and ornithological phenomena. Their conclusions are as follows : "There would appear to be most remarkable relations, both as regards seasons and localities, between the movements of birds and the initial outbreaks of invasion in foot-and-mouth disease in Great Britain. Some of these outbreaks, however, do not correspond with what are believed to be the known facts as regards bird movement. On the other hand, these facts are admittedly incomplete, and the circumstantial evidence as a whole is very far short of being able to establish a negative."

That a negative case is not established may be freely admitted, but we wish to examine, from an ornithological point of view, whether the indications in favour of a positive case are in fact so remarkable as the authors suggest. They themselves point to some serious discrepancies in the available evidence, and it does not seem helpful to suggest that these may be explicable, consistently with a positive case, by ornithological factors as yet unknown. The ornithologist is indeed tempted to retort that his present knowledge of bird migration rests on at least as sure a basis as the existing knowledge of the pathology of foot-and-mouth disease, and that unknown factors in the latter may equally well contain the clue to an explanation of quite another kind. Such speculation, however, is outside the scope of the present article.

Is the seasonal correspondence between migration and disease invasion indeed remarkable? The numbers of initial outbreaks in each month from January to December are as follows: $14,5,4,4,2,2,9,3,8,8,8$, 12. The numbers of years in which these outbreaks have occurred in each month are : 4, 4, 4, 4, I (or 2), $2,5,3,6,5,6,6$. From these figures the authors conclude that "by far the greater number of initial outbreaks have occurred in the months from September to January," the season of the principal immigrations from the east, and that from February to May " there are fewer initial outbreaks, and they are of less regular occurrence."

The available figures seem to be rather small to serve as a basis for such emphatic statistical deductions as those quoted, but taking them at the authors' valuation we find that several questions arise. There is, as they point out, a high incidence of initial outbreaks in the month of July, when migration is at its lowest ebb; there is a little immigration during the month, perhaps rather more than we know of, but certainly none on a scale in the least comparable with that of the autumn. There follows a period of low incidence of initial outbreaks in August, and then a period of higher incidence during September, October, and November, the chief months of autumn immigration from the Continent. But in December and January, as the authors themselves say, there is a still higher incidence. During these months there are

NO. 2828 , vOL. I I. 37 
"weather movements" similar in direction to the true autumn migrations, but they are on a much smaller scale. So far as autumn and winter invasions of disease are concerned, therefore, we may remark that, while corresponding migratory movements do exist, the incidence of outbreaks is not proportional to the magnitude of the movements, but is actually highest during the less important migration months of December and January, and at least as high during the relatively stagnant month of July as during the height of the autumn immigration in September, October, and November.

February is a difficult month-a period of crosscurrents at the turn of the migratory tide; it is a period of moderate incidence of initial outbreaks of disease. From March to June, however, we have the straightforward phenomenon of spring and summer immigration and passage from the south. In these four months the incidence of disease invasion remains relatively low. The ornithologist naturally asks why this great movement should be less important than the autumn and winter movements along the eastto-west route. It seems difficult to give any convincing ornithological reason, although a few possibilities suggest themselves, and the authors have not given us any other. To appreciate the point we should need to have information as to the seasonal incidence of the disease on the Continent, and of its frequency in France as compared with Belgium, Holland, Northern Germany, and Denmark. We are not, however, given this opportunity of envisaging the problem as a whole, and on the evidence before us we feel unconvinced that a close relationship is discernible between the seasonal phenomena of migration and the incidence of outbreaks of the disease. Certainly no quantitative correspondence is apparent between the numbers of initial outbreaks at different seasons and the magnitude of the appropriate bird movements.

Is the geographical correspondence between migration and disease invasion indeed remarkable? It is pointed out that the September, October, and November initial outbreaks occurred mainly in the part of England lying south of a line from the Bristol Channel to the Humber, the area chiefly affected by immigration at that season from countries to the east where the disease exists. It may be noted, however, that of I9 outbreaks in this area (against 5 outside) only $\mathrm{I}$ was in Suffolk and none in either Norfolk or Essex, although on the coasts of these counties a great part of the immigration from the east takes place. Nine were in Kent, Surrey, or Sussex, and 5 others further west but still near the south coast. A more detailed examination therefore tends to destroy some of the effect of the broad statement.

In December, January, and February, 20 out of $3^{\mathrm{I}}$ initial outbreaks-not an overwhelming preponderance -fell south of a line from the Severn to the Wash, i.e. in the area chiefly affected by immigration from the east at that season. Of these $\mathbf{r}$ was in Norfolk, $\mathbf{I}$ in Suffolk, 2 in Essex, 3 in Kent, and 6 in the south coast counties from Sussex to Devon. Of those outside the area, all but two were in the eastern half of the north of England, and certain northward movements of gulls up the east coast are suggested as the explanation. The case here is obviously not a strong one.

Of the initial outbreaks in March, April, and May, 3 were in Norfolk, $x$ in Essex, 2 in Kent, I in Surrey, and the other 3 towards the north-west. There is nothing in this which at all strongly suggests the lines of migration at that season, although perhaps also nothing inconsistent therewith.

Of the initial outbreaks in June, July, and August, 6 were in Kent, Surrey, Sussex, or Hampshire, I in Somerset, 4 in the Midlands, I in Lincolnshire, I in central Yorkshire, and $I$ in Cumberland. There is again nothing altogether inconsistent with the directions of migration at this season, but there is no indication of a distribution closely related to the principal movements either of the late summer or of the early autumn. The 5 July outbreaks in the Midlands and in the north - as against 3 in Kent or Surrey, and I in Somerset--are indeed difficult to explain on any theory of the kind, as the authors admit. During all three months there was a complete absence of outbreaks in an area of a dozen counties lying between the Wash and the Thames; yet this region is one which is particularly affected by late summer passage to the north and would be affected by any early autumn movements from the east.

The figures for the numbers of initial outbreaks in different areas are, of course, very small for statistical purposes and for the elimination of the effect of mere chance in the geographical incidence, but we have, again, taken them at the value which the authors appear to place upon them. Even so, we do not agree that the correspondence is remarkable. For although it may be possible to assign most of the apparent routes of disease invasion to the general directions of appropriate migratory movements, there is little indication of a quantitative relationship between the distribution of initial outbreaks and the importance of the different paths of bird immigration. Taking the distribution of initial outbreaks as a whole, it indeed seems difficult to find ground for saying much more than that they occurred most frequently in the extreme south-east of England, the part nearest the Continent, and decreased in frequency westwards and northwards.

Throughout this article we have taken the validity of the veterinary data for granted as being a matter outside the ornithologist's sphere of criticism, but there is one point on which we may at least raise a question. In the definition of "initial outbreaks of invasion" the authors include not only outbreaks occurring after an interval during which the country was free from the disease, but also " those arising simultaneously in parts of the country very remote from each other and having no possible connexion, except perhaps through the same agency, whatever it may be, whereby the virus is carried long distances and in certain directions." This seems to come perilously near begging the question, and our misgivings are aroused when we see from the illustrative charts how many of these nearly simultaneous outbreaks are in fact classed as separate invasions. Unconnected in any obvious way they doubtless were, but it seems scarcely permissible to select the data for an inquiry such as this on an assumed principle the validity of which depends NO. 2828 , VOL. I I 3 ] 
in some part on the subsequent argument. Nor are the charts altogether in accord with even the extended definition. We note, for example, the inclusion of outbreaks side by side in Kent with a difference of four days, and of two outbreaks in Devon with a fortnight's difference. For December r9I9 and January I920 no fewer than sixteen "initial" invasions are recorded, most of them in the south of England, and in the next ten months the total is brought up to twenty-nine. The elimination of such cases as these by a more rigid definition would materially alter the aspect of the data. Nor is it any answer to this objection to say that if these cases are connected it can only be by the same agency as connects original
British outbreaks with foreign outbreaks. The possible carriage of the virus by birds moving within the country is a different ornithological question from that of carriage from abroad, and it is the latter for which the data are presented and which is discussed in the paper.

We are interested to learn from an editorial note in the Journal that Sir Stewart Stockman is now experimentally investigating the possibility of the infection being carried by birds. The question remains open, and further research may well be useful. Here we can only express the opinion that the evidence put before us does very little towards establishing a prima facie positive case.

\section{The Utilisation of Volcanic Steam in Italy.}

$\mathrm{T}^{\mathrm{H}}$ increased desire for economic independence that accompanied the growth of national sentiment during the War has been shown very clearly in the intensified study and exploitation of natural resources ; and the welkin is still ringing with cries of " increase production," "back to the land," and " keep the home-fires burning." Examples of this worldtendency are apparent everywhere : in Central Europe, particularly, brown coal, water-power, and minerals have been greatly developed; in tropical countries, useful vegetable products have been increasingly exploited; and in many lands the rush for petroleum has

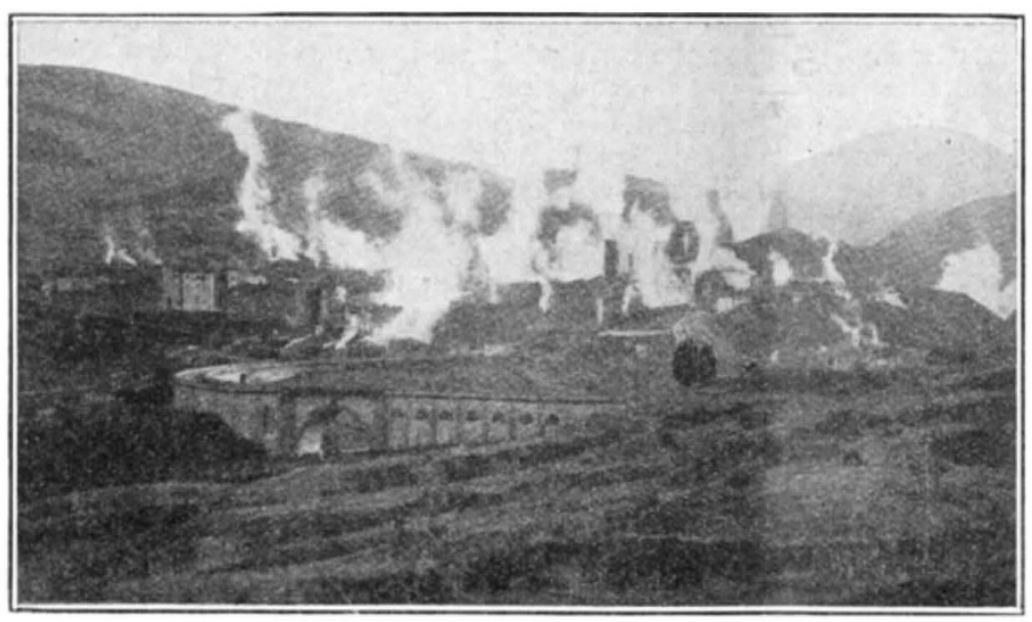

FIG. x.-General view of Larderello.

gathered momentum. Very little, however, has been heard as yet of attempts to utilise the interior heat of the earth, which many believe to be one of the most important potential sources of energy. Only in Italy has a definite and successful effort been made in this direction, namely, by utilising the natural steam which emerges from the earth in volcanic districts. The jets of steam ("soffioni ") and the pools of water, formed in small craters and maintained at boiling temperature by natural steam ("lagoni"), have been known for centuries, but for long were regarded by the peasants as manifestations of unseen and unfriendly powers. The discovery in them of boric acid in 1790 , the extraction of this acid on a commercial scale since $\mathrm{I} 8 \mathrm{r} 8$, and, in particular, the recent pioneer work of Prince Ginori Conti, in association with the Società Boracifera di Larderello, have completely transformed the picture, and revealed a source of wealth which may play an important part, not only in the future industrial development of Italy, but also in that of other countries that are blessed-and at times cursed-with volcanic activity.

The district which has been selected for study and exploitation forms, roughly, an elliptical area of about $2.5 \mathrm{sq}$. miles, lying south of Volterra and from 40 to 50 miles south-south-west of Florence. In this part of Tuscany, works for generating electrical power and for producing boric acid and other chemicals have been erected at Larderello, Castelnuovo, Sasso, Monterotundo, Lago, Lustignano, Sarrazzano, and, to the eastward, at Travale. The works are situated at the bases of hills dividing the valleys of the rivers Cecina and Cornia, and the roads are good, though winding. The volcanic nature of this district is shown by stretches of arid soil, the presence of many "soffioni" and "lagoni," and by the occurrence in their vicinity of sulphur, crystals of calcium carbonate with pseudomorphous growths of gypsum, larderellite (ammonium borate), and sassolinite (orthoboric acid).

For industrial utilisation the supply of steam from "soffioni" is not sufficient, and hence bore-holes, 16 in. diameter and from 200 to $500 \mathrm{ft}$. deep, are sunk and protected from caving by iron tubing. The steam issues at an average pressure of two absolute atmospheres, and at a temperature varying from $100^{\circ}$ to $190^{\circ} \mathrm{C}$., friction against the walls of the bore causing much of the super-heat. Recent drillings have released steam at a considerably higher pressure, and in quantities up to $60,000 \mathrm{~kg}$. (59 tons) per hour. At Larderello the actual available output is above 150,000 $\mathrm{kg}$. per hour from $\mathrm{r} 35$ bore-holes, and generally there is abundant evidence of enormous untapped supplies. The steam, which Prof. R. Nasini has shown to be radioactive, contains an average of 0.06 per cent. of boric

$$
\text { NO. } 2828 \text {, VOL. I I } 3]
$$

